\title{
PERISCOPE
}

\section{PANCREATIC CYSTS.}

In the symptoms accompanying pseudo-cysts of the pancreas Bérard and Cade draw attention to the great variations in size the cyst may undergo, a symptom which, though not always present, ought to be borne in mind. Variations in size of the abdomen in pseudo-cysts of the pancreas commonly occur but are ascribed to variations in distension of the stomach or of the colon. Diminution in size of a pseudo-cyst must be due to recurrent escape of the contents of the cyst by the pancreatic ducts.

The case they cite in support of their contention is that of a male, I7 years of age, who five months before cœliotomy had been seized suddenly with severe epigastric pain, accompanied by a rise of temperature and vomiting and some swelling of the stomach which subsided in the course of a few days. Dyspeptic symptoms, however, continued and he progressively lost weight. The more acute symptoms then returned and a very obvious tumour distended the epigastrium. It came from below the left costal margin to the middle line, was prominent, resistant, dull to percussion, and was about the size of a foetal head. To the right of the tumour the border of the liver was quite distinct. The urine was normal. Radioscopy after an opaque meal showed the stomach displaced to the left of the tumour which appeared to lie above the smaller curvature. The blood gave $4,800,000$ red and 6600 white cells with 62 per cent. of neutrophil polymorphonuclears. The absence of eosinophilia negatived an hydatid cyst.

While under observation the tumour diminished to half its size within twenty-four hours, though it could still be felt though deeply seated. The patient asserted that such variations had occurred previously. Later the abdomen was opened by a supra-umbilical median incision and above the stomach, between it and the liver a thin-walled, clear, iridescent cyst was found with deep and firm attachments which prevented excision. The cyst was therefore tapped and marsupialised. The contents of the cyst yielded evidence of its pancreatic origin though the fluid did not contain trypsin.

L. BÉrard Et A. Cade, "Sur un point intéressant de la séméiologie du pseudokyste du pancréas." (Journ. de mêd. de Lyon, I928, ix., 459).

\section{TRAUMATIC RUPTURE OF QUADRICEPS FEMORIS.}

A young man, 27 years of age, during gymnastic exercises fell from a horizontal bar to the floor and alighted in a squatting position. $\mathrm{He}$ felt an excruciating pain in the right thigh and was unable to rise. 